\title{
DIREITOS HUMANOS, GOVERNANÇA E DEMOCRACIA
}

\author{
Edson Teles*
}

O século $X X$ assistiu ao conflito de um movimento contraditório nas várias encenações do discurso dos direitos humanos. A efetivação dos direitos em políticas institucionais e nas normas do direito internacional caminhou conjuntamente ao uso indiscriminado da violência por parte dos estados. Foi o século dos genocídios, da limpeza étnica, do Holocausto e do desaparecimento forçado. Os estados envolvidos se caracterizaram pela sistemática violação aos direitos de seus cidadãos por meio de um repressivo aparato policial-militar. Em ato extremo destas condições, a humanidade conheceu um novo regime político, o totalitarismo, no qual o controle da vida passou a ser o elemento determinante da ação de governo.

As democracias nascidas nas últimas décadas surgem como herdeiras de regimes autoritários ou totalitários. Assim foi no Leste europeu após a queda dos governos pró-soviéticos, e, igualmente, com as poucas democracias substitutas do colonialismo tardio na Ásia e África. Na América Latina, o fim das ditaduras militares foi o momento originário da política democrática. Atualmente, a chamada "Primavera Árabe" experimenta o mesmo fenômeno. A marca do novo regime político, a democracia, é a promessa de desfazer as injustiças do passado.

\footnotetext{
* Doutor pela Universidade de São Paulo (USP), professor adjunto do Departamento de Filosofia na Universidade Federal de São Paulo (Unifesp). E-mail: edsonteles@gmail.com.
} 
$|56|$

Direitos humanos, governança e democracia...

Em sociedades carentes de vários direitos (saúde, alimentação digna, educação de qualidade, água, saneamento, etc.) e repletas de vítimas das mais variadas violências, especialmente por parte do Estado, a reflexão filosófica coloca em questão a ação política.

As sociedades resultantes de passado violento se veem com o problema de como conciliar o passado doloroso com um presente democrático, administrando os conflitos que não se encerraram com a mera passagem institucional de um governo de exceção para um democrático. Isto porque as violações aos direitos humanos, que atingiram os indivíduos e as instituições, alteraram significativamente a subjetividade destas sociedades e mantiveram-se após o nascimento da democracia.

Nestas condições se faz necessário à filosofia interrogar o conceito de homem, conhecer sua história e, principalmente, buscar compreender o poder de legitimação das relações sociais estabelecido pelo discurso e pela estrutura dos direitos humanos. Não se trata de dizer contra tais direitos ou de se opor ao conceito de humanidade implícito no cosmopolitismo deste discurso. Sabemos que boa parte das garantias políticas e civis dos estados de direito e das democracias contemporâneas advém de definições como a de "crime contra a humanidade", ou a de "direito à memória e à verdade". São conceitos que se efetivaram em acontecimentos jurídicos, transformando o direito internacional e possibilitando certa limitação na ação de violação da dignidade humana por parte dos estados nacionais.

Os direitos humanos, nascidos nas declarações de direitos dos séculos XVII e XVIII ${ }^{1}$ como estratégia da burguesia emergente contra o poder despótico dos reis e visando proteger o novo indivíduo e suas propriedades, viriam a se transformar, no século XX, em discurso e ação de resistência e libertação contra a opressão. Aparentando realizar o projeto iluminista de sujeição

\footnotetext{
${ }^{1}$ Referimos-nos especialmente às declarações inglesa (Bill of Rights, de 1688), francesa (Déclaration des Droits de L'Homme et du Citoyen, de 1789) e norte-americana (Bill of Rights, de 1791).
} 
da política à razão e à lei, os direitos humanos tomam parte dos movimentos de dissidência e ruptura, marcando a queda do Muro de Berlin, do Apartheid e o fim das ditaduras militares na América Latina. Em um movimento paralelo, o discurso, até então proferido preferencialmente nos movimentos sociais, ocupa novos lugares nas democracias ao ser incluído nas convenções, falas dos especialistas e nas políticas públicas.

A democracia nos leva a algumas questões, sobre as quais precisamos aprofundar para a compreensão da ação política na atualidade: qual o estatuto da promessa iluminista e moderna de emancipação da humanidade? Como e por que as democracias têm feito a tradução das práticas sociais para a linguagem da lei e dos direitos? (Cf. Douzinas, 2009). Seria a ação política democrática uma terapia social para o sofrimento das mais variadas vítimas?

\section{Natureza e política, o poder soberano}

No estado moderno, e de acordo com seus ordenamentos nacionais, o soberano é a figura máxima a regular a vida e a política. Sua legitimação ocorre por meio da consideração da oposição entre natureza e lei. Platão já havia abordado o conflito entre phýsis e nómos, no Livro $X$ das Leis, procurando se contrapor a esta oposição e construindo a ideia da prevalência das coisas que podemos fazer em relação às coisas que nos são dadas a conhecer pela natureza. A oposição entre natureza e lei voltará com força na filosofia política do século XVII, quando Hobbes mostra o conflito entre natureza e commonwealth, apontando na identificação da natureza com a violência a justificação do poder absoluto do soberano (Cf. Hobbes, 1979, cap. XIV).

Na teoria política de Hobbes não ocorre uma sociabilidade natural entre os homens; antes disto, há uma desconfiança que os fazem dedicarem-se mais à dominação do que à sociedade civil. "O direito de natureza (...) é a liberdade que cada homem possui de usar seu próprio poder (...) para a preservação (...) de sua vida" (ibidem, cap. XIV, p. 78). A liberdade natural, o que legitima ou autoriza o direito, configura-se pela ausência de obstáculos 
$|58|$

Direitos humanos, governança e democracia...

para a necessária conservação da vida. Nesta situação, o medo da morte violenta relaciona-se com a condição vulnerável do homem natural, pondo em risco qualquer tentativa de sociabilidade igualitária ou justa. É a partir do desejo e da necessidade de se conservar a vida que as leis de natureza cedem e obrigam, por um ato da razão, o direito positivo. No gozo da liberdade jurídica, construção artificial do consentimento ao contrato, o medo da morte e da violência leva à transferência de todo o poder natural para o soberano, quem agora poderá fazer o necessário para a proteção da vida.

O direito natural, fonte originária do ordenamento da sociedade civil no estado moderno, deixa de se derivar do kósmos, ou do divino, ou da república ideal, como na antiguidade e no medievo, e passa a ter como origem a natureza humana. $\mathrm{O}$ sujeito é colocado no centro da nova ordem social. E, se não há uma fundamentação fora do mundo para instituir as regras da nova sociedade, o movimento de inclusão do direito natural nas leis civis configura-se como uma secularização da natureza humana. A grande força do acordo consentido via contrato social encontrase na violência existente até a origem do pacto e na força dispensada na preservação da vida. Ainda que a subjetividade individual do homem em natureza tenha resultado na lei civil, a partir de sua institucionalização consentida, toda decisão sobre a necessidade de agir ou não para a proteção da vida passa a ser uma potência restrita ao poder soberano (ibidem, cap. XVII, pp. 105-106).

Sendo o soberano o único dotado de poder sobre a vida e dispondo do uso legítimo da violência, carrega em si o estado de natureza e a sociedade, em um lugar indefinido entre violência e lei. A lei oriunda do contrato social compreende tanto o nómos quanto a phýsis, todavia esta última não ressurge como estado de natureza, algo externo à sociedade, mas travestida em estado de exceção. Assim sintetiza o filósofo italiano Giorgio Agamben:

Estado de natureza e estado de exceção são apenas as duas faces de um único processo topológico no 


\begin{abstract}
qual, como numa fita de Moebius, o que era pressuposto como externo (o estado de natureza) ressurge agora no interior (como estado de exceção), e o poder soberano é justamente esta impossibilidade de discernir externo e interno, natureza e exceção, phýsis e nómos (Agamben, 2002, p. 43).
\end{abstract}

Se no antigo regime o nascimento conferia ao indivíduo sua condição de súdito e ao príncipe sua potência em ser rei, no Estado moderno a natalidade marca a entrada de um novo sujeito no mundo, cedente desde então de seus direitos ao soberano da nação. "Os direitos são atribuídos ao homem (ou brotam dele), somente na medida em que ele é o fundamento, imediatamente dissipante (...) do cidadão" (idem, 2004, p. 135). Em termos históricos, o movimento de inclusão da vida na lei remonta às primeiras declarações de direitos dos homens, ao definir o nascimento (ou sua condição biológica) como o fundamento da conservação da vida.

Para a filosofia política de Hobbes, o poder político soberano caracteriza-se mais pela conservação do direito de se apropriar da vida de qualquer um (Hobbes, 1979, cap. XXI). A sobrevivência do estado de natureza no interior do estado corresponde ao ato de proteger a vida; momento no qual a violência passa a ser direito e o direito transforma-se em violência exclusiva do Estado. É o modo que o homo hominis lupus encontrou para habitar a "terra de ninguém entre a casa e a cidade" (Agamben, 2002, p. 98).

\title{
A vida como paradigma da política
}

No século $X X$ vivemos o momento histórico no qual o estado de exceção foi transformado em regra, especialmente pelos regimes totalitários, instaurando a repressão legalizada e possibilitando a eliminação biológica de adversários políticos e grupos identitários. Os anos de Guerra Fria e subsequentes incrementaram a substituição das declarações de estados de 
$|60|$

Direitos humanos, governança e democracia...

exceção por doutrinas de segurança nacional, fazendo da exceção uma técnica de governo. Desde então, a prática de um estado de emergência constante tornou-se paradigma para a governança ${ }^{2}$ e para a ação política. A medida de exceção não é apenas um direito especial do Estado, mas um poder do soberano de suspender o próprio ordenamento.

Para os gregos havia duas palavras para exprimir a ideia de vida: zoé - a condição de vivente de todos os seres vivos, homens, animais ou deuses; e bíos - o modo de viver de um indivíduo ou de um grupo. De modo distinto à vida qualificada pelo convívio público na pólis (bíos), os aspectos de reprodução e subsistência caracterizavam a vida natural e mantinham-se dentro do âmbito privado do oîkos (zoê), a casa (Aristóteles, 2000, 1252a). No entanto, no contemporâneo, alguns autores indicaram o movimento de inclusão do biológico nos assuntos da esfera pública.

Michel Foucault definiu a política moderna como a expansão da biopolítica, por meio do controle disciplinar levado a efeito pelas tecnologias dos "corpos dóceis", uma espécie de animalização do homem em sociedade (cf. Foucault, 2009). Antes dele, Hannah Arendt também havia apontado a crescente interferência da vida biológica na política. Aimplicação da inclusão da vida na ordem é a indeterminação das distinções entre as esferas públicas e privadas, ou como argumentou Hannah Arendt, a confusão entre o político e o biológico (Arendt, 2010, pp. 26-96).

\footnotetext{
${ }^{2}$ Escolhemos o termo governança porque diz respeito a meios e processos utilizados para produzir resultados eficazes no trato das necessidades básicas da população, o que, nos parece, marca a ação política democrática. Para James Rosenau, "governança é um fenômeno mais amplo que governo; abrange as instituições governamentais, mas implica também mecanismos informais, de caráter não governamental, que fazem com que as pessoas e as organizações dentro da sua área de atuação tenham uma conduta determinada, satisfaçam suas necessidades e respondam às suas demandas" (Rosenau, 2000, pp. 15-16).
} 
O que melhor caracteriza a política moderna, segundo Giorgio Agamben, não é o duplo movimento de inclusão/exclusão da vida nos cálculos do Estado, mas o fato de que quanto mais a exceção se torna a regra, mais a vida toma o mesmo lugar da política e "exclusão e inclusão, externo e interno, bíos e zoé, direito e fato entram em uma zona de irredutível indistinção" (Agamben, 2004, p. 16). Portanto, o decisivo para a compreensão do moderno não é o fato de a exceção caracterizar-se como regra, mas a vida nua encontrar-se na vida política. A democracia moderna é marcada pelo paradoxo de buscar a emancipação do homem por meio da vida nua - o mesmo elemento que implica sua submissão. Por um lado, "o poder estatal faz do homem enquanto vivente o próprio objeto" e, por outro, "o homem vivente se apresenta não mais como objeto, mas como sujeito do poder político". O fundamento oculto da política moderna, a soberania, desloca-se de seu lugar central nas instituições do Estado e liberase na cidade, tornando-se simultaneamente "o sujeito e o objeto do ordenamento (...), ponto comum tanto da organização do poder estatal quanto da emancipação dele" (idem, 2002, p. 17).

No contemporâneo, a grande apropriação do biológico pela estrutura institucional do Estado foi realizada pelos regimes totalitários do século XX. Para se efetivar, tais regimes eliminaram não só a esfera pública, mas também qualquer possibilidade de espontaneidade humana, interferindo nos assuntos da vida privada. Para tanto, destruíram as redes sociais de comunicação e convivência, visando mobilizar as massas despolitizadas, segmento social crescente no período. Estas massas se definiam pelo volume grande de pessoas, pela apatia e indiferença política e encontravam-se atomizadas socialmente (cf. Arendt, 1989). O colapso do estado-nação e as consequências da Primeira Guerra Mundial criaram as condições, com o desemprego e a inflação, para desfazer qualquer característica coletiva de grupo social.

Para o totalitarismo não bastava a eliminação dos opositores, mas havia a necessidade da posse de todo o tecido social, destruindo qualquer relação social, visando impor o controle absoluto e incondicional. E, contrariamente às razões 
|62|

Direitos humanos, governança e democracia...

do estado moderno para seus atos de violência institucional, o terror dos regimes totalitários não visava e não desencadeava ações producentes e utilitárias. O novo regime colocou em questão os conceitos tradicionais de poder político ao apresentar uma concepção inteiramente nova e sem precedentes na qual há um desprezo máximo ao realismo social, aos interesses nacionais e, o mais marcante, aos interesses utilitários do estado. De modo distinto aos outros regimes políticos, no totalitarismo o estado em si não é mais o instrumento de realização da política, mantendo-se como fachada para o mundo não totalitário. A estrutura de poder se realiza no partido e se materializa na polícia política, a instituição executiva do governo e do líder do movimento. É a polícia que decide sobre quem é o inimigo objetivo, ou seja, quem são aqueles cuja mera existência implica em contradição com a ideologia do governo, independente do que pensem, façam ou falem. Enquanto instrumento direto de aplicação da política, a polícia não se encontra acima da lei, mas é ela a própria força da lei.

O surgimento do totalitarismo tornou evidente a crise dos direitos humanos. Os apátridas, sujeitos desterrados do pertencimento a um coletivo político, colocaram em relevo a terrível condição de seres humanos que, por não gozarem de direitos e por não serem protegidos pelas leis de um ordenamento nacional, não eram nada além de meros seres viventes. Mesmo a ideia de asilo político ou econômico perdeu sua função diante do quadro de colapso do estado-nação. Como poderia o apátrida solicitar este direito aos estados estrangeiros se ele encontrava-se naquela situação por ter nascido na "raça impura" ou na "classe inimiga"? Segundo Hannah Arendt, o totalitarismo não escolhia suas vítimas pelo que elas tinham feito ou pelo pensamento que propunham, mas por sua condição biológica, pelo fato de terem nascido em determinada condição. A indeterminação de uma condição ilícita ou de transgressão à lei destrói o nexo fundamental presente em qualquer ordenamento jurídico dos estados modernos entre a ação e sua consequência, ou ainda, a distinção entre criminoso e inocente (cf. Lafer, 1991). 
Hannah Arendt refletiu sobre a necessidade de uma comunidade política para que o sujeito tenha direitos, de uma esfera pública que valorize as opiniões e torne as ações eficazes. A concepção dos direitos humanos fundada na natureza, no Homem, ao ser enunciada no singular, desconsidera a pluralidade humana existente na política. Tal qual já havia sido feito por outros filósofos, ${ }^{3}$ a autora de Origens do totalitarismo contesta a fundamentação de qualquer direito ou esfera política em um elemento externo a eles, neste caso, a natureza do ser humano. Sua proposição básica é a de que não nascemos iguais, mas tal possibilidade resultaria da ação e da organização política, do pertencimento a uma coletividade. Foi da cena dos campos de concentração, na qual os homens encontravam-se reduzidos a simples seres viventes, que Arendt elaborou a concepção de artificialidade do direito e da política. Portanto, sua crítica aos direitos humanos não objetiva a existência deles enquanto tal, mas à sua fundamentação na natureza, o que acaba por gerar a desqualificação da política, reduzida a algo externo e anterior às relações sociais.

\section{O discurso dos direitos humanos}

Há um determinado poder no uso público dos discursos que se relaciona diretamente com a ordem das leis e das instituições, na medida em que os sujeitos que os pronunciam não têm necessariamente domínio sobre suas realidades ou durações, nem mesmo podem dizer que lhes pertencem. Pressupomos que a produção do discurso sofre o controle e a seleção de determinados procedimentos que visam assegurar as

\footnotetext{
${ }^{3}$ Sobre a importância do momento de fundação de determinado coletivo para a legitimação da ação política, cf. Maquiavel, 2000. Em H. Arendt há um estudo sobre a importância do momento fundacional para estabelecimento da legitimidade política no artigo "O que é autoridade?" (1997, pp. 127-187).
} 
$|64|$

Direitos humanos, governança e democracia...

implicações de seus usos e prevalecer sobre sua possível ocorrência contingencial. Mais do que denotar uma tradução das relações sociais de dominação e resistência, os discursos são eles mesmos aquilo "pelo que se luta, o poder pelo qual queremos nos apoderar" (Foucault, 2008a, p. 10).

Há uma predisposição, na sociedade moderna, de validar as ações por meio de um discurso considerado verdadeiro. É como se fosse mais importante aquilo que é dito, do que o agir. E, para se encontrar de posse do discurso verdadeiro, é preciso se submeter às regras e controles que o determinam, o que limita ou anula o acesso a sua produção e uso. Dessa forma, para se utilizar do discurso é preciso estar preparado, condicionado, qualificar-se para pronunciá-lo, de modo que se determina um conjunto reduzido dos especialistas autorizados a esta fala. Se, por um lado, os discursos são construções sujeitas a mecanismos de controle, sua difusão e partilha também condicionam aqueles que o escutam, na medida em que se reconhecer em um destes discursos pode definir sua pertença a determinado coletivo. Mais do que isto, pode ainda legitimar ações que corroborem os valores mobilizados pelo discurso, concedendo certa soberania ao sujeito que dele participa. ${ }^{4}$

Participando do consenso da política contemporânea, o discurso dos direitos humanos legitima, paradoxalmente, tanto a resistência do indivíduo frente às violências sofridas quanto a política dos estados nacionais, os maiores violadores de direitos. Desta forma, o militante e o ministro, o sem-terra e as forças de segurança, o destituído e a grande mídia são seus usuários. A ideia fundamental deste discurso é a de que há um grande contingente de indivíduos que sofrem alguma injustiça ou se encontram carentes em suas necessidades básicas. A partir desta condição social, o discurso dos direitos humanos, quando se

\footnotetext{
${ }^{4}$ Interessante notar que, para Foucault, a análise dos discursos demanda três passos metodológicos: "Questionar nossa vontade de verdade; restituir ao discurso seu caráter de acontecimento; suspender, enfim, a soberania do significante" (ibidem, p. 51).
} 
encontra de posse do estado, autoriza o "império da lei", através de seus "tribunais" e de "cada órgão da sociedade", a "decidir sobre os direitos e deveres" das vítimas de violações. Um novo modo de ação é validado para que "o ser humano não seja compelido (...) à rebelião contra a tirania e a opressão", ou seja, para que não tenha ele mesmo que agir politicamente em prol da transformação de seu estado de opressão. ${ }^{5}$

O novo modo de agir na política, corroborado pelo discurso em questão, vem substituindo há algumas décadas o movimento social organizado independente do ordenamento dos estados de direito, substituindo também as formas tradicionais da democracia representativa. Em lugar da ação política, os novos atores sociais são instados a fomentar, no teatro de fabricação dos resultados, a governança do sofrimento através de uma mudança social contabilizada nos índices de desenvolvimento da humanidade. Na nova forma da política, como já teorizou Hannah Arendt, os instrumentos e a racionalidade da atividade terapêutica substituem a possibilidade de ruptura por um fazer planejado enquanto artefato de controle da ação (Arendt, 2010, pp. 274-286).

\section{A terapia do sofrimento social}

A ideia da política como uma terapia social, a fim de evitar ações de ruptura, não é novidade do contemporâneo. No fim do século VII a. C., intensificou-se na Grécia uma busca desenfreada para acumular as novas riquezas obtidas no comércio com o Oriente. Tal situação gerou uma forte desigualdade econômica e social e colocou em crise a ordem social da pólis, com a ocorrência de violência e conflitos generalizados. "É a maldade dos homens, seu espírito de hybris, sua sede insaciável de riqueza que produzem naturalmente a desordem" (Vernant, 1986, p. 61). Segundo Aristóteles, um acordo somente foi possível por uma mudança

\footnotetext{
${ }^{5}$ Citações extraídas da Declaração Universal dos Direitos Humanos,
} da ONU (1948). 
|66 |

Direitos humanos, governança e democracia...

cultural dos mais ricos, que abriram mão de parte de suas riquezas ou do aumento delas para fornecer o mínimo ao demos e, desse modo, manter a estrutura social sem profundas transformações (Aristóteles, 2000, Livro II, 1267b).

No século XIX que a ideia de uma ação voltada à satisfação das necessidades básicas será retomada como modo possível e eficaz para o estado da necessidade criado com o contrato social. O criminalista alemão Franz von Liszt, dentre outros, defendia uma concepção determinista do homem, com uma visão do delito como reflexo de seu próprio caráter perigoso (social e individualmente determinado) e uma crença na possibilidade de sua correção através de políticas sociais terapêuticas (cf. Von Liszt, 2007).

Na filosofia, Nietzsche atribuía a decadência da política moderna às preocupações que a restringiam à tentativa de atender necessidades urgentes, momentâneas (Nietzsche, 2004, pp. 127-128). Há, no estado moderno, um determinado tipo de homem, ora carente, ora saciado, que é conduzido adiante pelas mãos da política, de modo que o funcionamento eficiente do governo gera, no máximo, indivíduos momentaneamente satisfeitos (idem, 2007). Por mais conforto e durabilidade que se possa proporcionar à vida, isto não é suficiente para que o homem transponha sua condição de escravidão. A saciedade alcançada tem efeito passageiro e sempre lança os homens novamente no mesmo ciclo de necessidades e carências, cuja satisfação devolve os homens à condição escrava.

Segundo Nietzsche, a democracia "não é meramente uma forma de degradação da organização política, mas uma forma de degradação, ou seja, de apequenamento do homem, sua mediocrização e rebaixamento de valor" (idem, 1987, p. 62). O problema gerado pela ação terapêutica é que se a instituição pública tem por tarefa o atendimento das carências e debilidades humanas, necessariamente ela conduz adiante a fraqueza nos homens, comprometendo o futuro da humanidade e da própria política. 
A opção pela terapia social pensada no fim do século XIX e legitimada como política de estado com a democracia contemporânea, através do consenso institucional fabricado pelo e em torno do discurso dos direitos humanos, opera a construção de um léxico no qual antigos termos são ressignificados diante de novas teorias ou ideias. As novas noções do agir social apresentam-se como valores naturais, sem história própria, validados pela existência de um ser humano universal e deixando no esquecimento os conflitos e singularidades passadas e presentes. Deste modo, torna impossível a criação de um discurso contrário e crítico ao consenso fabricado. Por não ser apresentado como resultado das relações de dominação e resistência, de poder e violência, o fazer terapêutico obtido pelo consentimento da cidadania se estabelece como uma negociação. ${ }^{6}$

No entanto, parece-nos necessário adotar a concepção foucaultiana de que o discurso, ao contrário de sua concepção enquanto consenso, é resultante das violentas disputas de poder presentes no estado democrático de direito. Em vista disto, a interrogação sobre os conceitos envolvidos em sua formulação nos permite identificar as metamorfoses sofridas pelas formulações clássicas dos direitos humanos no contemporâneo.

\section{A democracia dos direitos humanos}

Juntamente com o colapso do estado-nação entrou em crise a ideia de direitos humanos, pois sem a proteção de um estado, de uma nação, de uma comunidade política, aos homens era

${ }^{6}$ Exemplo da concepção dos direitos humanos como negociação e consenso é a carta do Estado brasileiro ao Conselho de Direitos Humanos da ONU, datada de 19 de julho de 2010, na qual se propõe a negociação com os regimes autoritários com o intuito de evitar a "politização". Para o Itamaraty, o problema é que, "hoje, o Conselho de Direitos Humanos da ONU vai diretamente para um contencioso", o que provocaria a reação contrária dos violadores de direitos. Artigo sobre o tema disponível em www.itamaraty.gov.br, consultado em setembro de 2010. 
|68|

Direitos humanos, governança e democracia...

negado o "direito a ter direitos". Tal é o paradoxo dos direitos humanos: sua condição de direitos inalienáveis está baseada na concepção de um homem abstrato, ${ }^{7}$ que não existe em parte alguma, ao mesmo tempo em que os homens reais, concretos, encontram-se desprotegidos e entregues às violações de direitos por parte do mesmo estado que deveria protegê-los. ${ }^{8}$ Caso emblemático de um estado que faz uso do discurso dos direitos humanos de modo paradoxal é o lamentável "Massacre do Pinheirinho", no qual instituições que se utilizam da legitimação por meio deste discurso - ele é ensinado nas escolas da Polícia Militar - são as mesmas que violam os direitos com a violenta reintegração de posse testemunhada em janeiro de 2012, em São José dos Campos (Estado de São Paulo). Sem o pertencimento a uma organização política há quem ou o quê proteja este indivíduo desenraizado e o caráter inalienável dos direitos humanos perde sua potência.

Apesar do paradoxo experimentado nos direitos humanos, as democracias do século $\mathrm{XX}$ surgiram justamente pela proclamação de seu triunfo sobre os regimes totalitários e autoritários. Tal vitória indica a concepção da democracia como o regime do "mais eficaz" e "mais justo" na proteção da vida afinal nasceu para desfazer as injustiças do passado. Os novos regimes, formados por dispositivos de soberania, são identificados com o estado de direito. Democracia e estado de direito tornaramse praticamente uma única coisa, com os direitos configurando o próprio sentimento coletivo. O jurídico diz ao legislativo o que deve e o que é melhor a ser feito, como se fosse a incorporação da vontade da nação e da sabedoria sobre as regras e leis (Rancière,

\footnotetext{
${ }^{7}$ Sobre a crítica dos direitos humanos, cf. Burke, 1997; Paine, 1989; Marx, 2010; Arendt, 1989 e Villey, 1986.

${ }^{8}$ Para uma genealogia do conceito de Homem inscrito nas declarações de direitos humanos e sobre o paradoxo deste conceito em legitimar, através de um discurso público, ações de proteção e, ao mesmo tempo, de violações dos direitos, cf. Costas Douzinas, 2009.
} 
1996). É a marca da submissão do político ao ordenamento, justificada pela ideia de que a regra é preferível ao autoritário, pois possibilita a liberdade civil. As práticas e movimentos sociais são tratadas como um caso de justiça, objetivadas em processo judicial ou alguma política pública.

Na democracia consensual, fundamentada no discurso dos direitos humanos, os danos sofridos pelo sujeito político são objetivados por meio do tratamento da falta, com políticas positivas de reconhecimento e diminuição da injustiça. O sujeito ativo da democracia é identificado com a parte da sociedade capaz de se envolver com a solução do problema. É como se a vítima, impedida de ser agente de seu problema por não fazer mais parte de nenhuma parcela dos que têm acesso aos direitos e sendo apagada da contagem sem resto do consenso, se tornasse um objeto. A objetivação do dano em ações de governança provoca a exclusão da vítima da ação política. A maior marca da democracia dos direitos humanos é a liberação da vida, valorizando a liberdade e a felicidade dos homens no mesmo espaço onde se imagina sua submissão às regras.

\section{Bibliografia}

AGAMBEN, G. Homo Sacer: O poder soberano e a vida nua. Tradução: Henrique Burigo. Belo Horizonte: UFMG, 2002.

Estado de exceção. Tradução: Iraci D. Poleti. São Paulo: Boitempo, 2004.

ARENDT, H. Origens do totalitarismo. Tradução: Roberto Raposo. São Paulo: Companhia das Letras, 1989.

Entre o passado e o futuro. Tradução: Mauro

W. Barbosa de Almeida. São Paulo: Perspectiva, 1997.

A condição humana. Tradução: Roberto Raposo. Rio de Janeiro: Forense Universitária, 2010. 
170

Direitos humanos, governança e democracia...

ARISTÓTELES. A Política. São Paulo: Martins Fontes, 2000.

BURKE, E. Reflexões sobre a revolução em França. Brasília: UnB, 1997.

DOUZINAS, C. "O triunfo dos direitos humanos". In: O fim dos direitos humanos. São Leopoldo: Unisinos, 2009.

FOUCAULT, M. A ordem do discurso. Tradução: Laura F. de A. Sampaio. São Paulo: Loyola, 2008a.

Segurança, Território, População: Curso dado no Collège de France (1977-1978). Tradução: Eduardo Brandão. São Paulo: Martins Fontes, 2008b.

Vigiar e punir: Nascimento da prisão. Tradução: Raquel Ramalhete. Petrópolis: Vozes, 2009.

HOBBES, T. Leviatã ou matéria, forma e poder de um Estado eclesiástico e civil. São Paulo: Abril Cultural, 1979.

LAFER, C. A reconstrução dos direitos humanos - Um diálogo com o pensamento de Hannah Arendt. São Paulo: Schwarcz, 1991.

LEFORT, C. A invenção democrática - Os limites do totalitarismo. São Paulo: Brasiliense, 1983.

MAQUIAVEL. O príncipe. Tradução: Lívio Xavier. Rio de Janeiro: Ediouro, 2000.

MARX, K. Sobre a questão judaica. Tradução: Nélio Schneider. São Paulo: Boitempo, 2010.

NIETZSCHE, F. W. "Além do bem e do mal. Prelúdio para uma filosofia do futuro." In: Coleção Os Pensadores. Tradução: Rubens Rodrigues Torres Filho; Seleção: Gérard Lebrun. São Paulo: Nova Cultural, 1987.

Aurora. Tradução: Paulo César de Souza. São Paulo: Companhia das Letras, 2004. 
. "O estado grego". In: Cinco prefácios para cinco livros não escritos. Tradução: Pedro Sussekind. Rio de Janeiro: 7Letras, 2007.

PAINE, T. Os direitos do homem. Tradução: Maria Tereza S. R. de Souza. Petrópolis: Vozes, 1989.

RANCIÈRE, J. O desentendimento. São Paulo: Ed. 34, 1996.

ROSENAU, J. N. “Governança, Ordem e Transformação na Política Mundial”. In: Rosenau, James N. e Czempiel, ErnstOtto. Governança sem governo: Ordem e transformação na política mundial. Brasília e São Paulo: UnB e Imprensa Oficial do Estado, pp. 11-46. 2000.

VERNANT, J-P. As origens do pensamento grego. Tradução: Ísis B. B. da Fonseca. São Paulo: Difel, 1986.

VILLEY, M. "Polémique sur les 'droits de 1'homme' “. In: Les Études Philosophiques. Paris: PUF, avril-juin, 1986.

O direito e os direitos humanos. Tradução: Maria Ermantina de A. P. Galvão. São Paulo: Martins Fontes, 2007.

VON LISZT, F. A teoria finalista no direito penal. São Paulo: LZN, 2007. 